\title{
Periodismo en América Latina: colonialidad y traducción cultural
}

\section{Jornalismo na América Latina: colonialidade e tradução cultural}

Aníbal Orué Pozzol

Resumen: El presente artículo discute la relación entre sujetos en la práctica periodística latinoamericana. Partiendo del entendimiento del periodismo como una de las expresiones de la modernidad, el texto avanza - desde la perspectiva de pensadores Latinoamericanos como Fausto Reinaga, Jesús Martín Barbero, Juan Díaz Bordenave y otros - hacia una propuesta epistemológica que expresa una práctica del oficio desarrollada desde la región.

Palabras clave: Periodismo; América Latina; traducción; colonialidad del texto.

Resumo: $O$ artigo discute a relação entre sujeitos na prática jornalística latino-americana. Partindo do entendimento do jornalismo como uma das expressões da modernidade, o texto avança - desde uma perspectiva de pensadores Latino-americanos como Fausto Reinaga, León Cadogan, Jesus Martín Barbero, Juan Díaz Bordenave e outros - até uma proposta epistemológica que expresse uma prática do ofício desenvolvida desde a região.

Palavras-chave: Jornalismo; América Latina; tradução; colonialidade do texto.

1 Universidade Federal da Integração Latino-Americana (UNILA). Foz do Iguaçu, PR, Brasil; Universidad Nacional del Este (UNE). Ciudad del Este, Paraguay; Centro de Estudios Rurales Interdisciplinarios (CERI). Asunción, Paraguay.

https://orcid.org/0000-0003-3679-0617 E-mail: aoruepozzo@gmail.com 


\section{Introducción general}

El presente artículo discute algunos cambios que los amplios y diversos procesos sociales, políticos y culturales han introducido en la teoría y en la práctica periodística latinoamericana. Partiendo de una perspectiva histórica, el texto enfatiza las transformaciones presentes en sociedades latinoamericanas en los últimos 40 años. Más específicamente, cómo es posible pensar la comunicación y el periodismo en la región, desde experiencias que penetran en los poros de la piel, en los cuerpos y mentes de la población, principalmente de sectores subalternos. Para tal efecto, intentaré desarrollar un camino de forma a buscar nuevas perspectivas al entendimiento del campo comunicacional y periodístico y, por su vez, apuntar horizontes que el desafío de enfrentarlos nos depara en la región, y más concretamente, en determinados países sudamericanos.

Así, voy abordar esta propuesta desde dos puntos específicos. El primero, es una discusión epistemológica que compete al campo periodístico de una manera más concreta: la relación sujeto-objeto presente en esta práctica profesional, que se constituye y conforma como distintiva en los últimos cien años. En segundo lugar se discute cómo y de qué manera el periodismo adopta, interpreta y desarrolla modelos pertenecientes a otras o culturas, a otras formas de experiencias particulares, incorporándolas como modelos universales. Para tal efecto, recurriré al concepto de traducción o mediación cultural, de manera a poder, desde los mismos, discutir las prácticas culturales de otras regiones que se incorporan al periodismo de América Latina.

\section{Periodismo y la relación sujeto/objeto: barreras por romper o una relación que no se agota en la objetividad}

Voy a iniciar este análisis, discutiendo la relación que aparentemente se presenta en el texto o narrativa periodística entre el sujeto, es decir, aquel que inicialmente observa (fuente), y otro sujeto a quien se le comunica un hecho social, quien posteriormente lo interpreta y transmite de diversas formas y maneras (divulgador, difusor, mediador, periodista); este 
hecho, más tarde lo presenta como información a un público amplio. Sin embargo, podemos observar que la misma atraviesa varios momentos o varias mediaciones sociales y culturales: no es solo y únicamente un hecho, tiene un contexto y es éste el que se explicita en la difusión, transmisión o en el narrar/contar el hecho. Comenzaré introduciendo una discusión crítica en esta relación sujeto/objeto que, para muchos, siempre fue aquella que definió la práctica periodística. Estas distintas maneras o formas de "llevar" información de un lugar a otro tienen, en el mundo occidental, una larga data. De alguna manera Habermas (1994) nos describe una parte de este proceso analizando lo que sería el mundo europeo moderno. Sin embargo, y este es uno de los puntos centrales de la crítica, esta práctica social no se limita al mundo occidental. El mundo no occidental, en este caso América Latina, ha desarrollado diferenciadas prácticas de llevar información de un lugar a otro y de contar un hecho social. Lo complicado es sustentar a un determinado modelo como universal. Es decir, como la única forma o manera de narrar o contar los acontecimientos, como ejemplos al cual llegar. Si observamos las diferentes sociedades previas a la invasión colonial del492 en América, se nos presentan diferentes formas de llevar/almacenar la información de un espacio social a otro, de un territorio a otro. La información contenida en los Códices Náhuatl (LEÓN PORTILLA, 1961), en los kipus del Tiwantinsuyo (BENÍTEZ, 2000), en las narrativas orales guaraní (CADOGAN, 1959) y en las antiguas historias de los Mayas-Quiches (POPOL VUH, 1960), por dar un ejemplo, constituyen otras tantas formas o maneras en que estas sociedades empleaban una determinada tecnología para llevar/almacenar la información de un lugar a otro; pero, tampoco podemos pensar estos ejemplos como modelos a seguir, a semejanza de otros modelos en otras regiones del mundo occidental y no occidental.

Desde una perspectiva occidental, el periodismo fue en algún momento caracterizado como una de las expresiones de la modernidad. Desde este énfasis emerge la posibilidad de un periodismo moderno juntamente con la formación de Europa y la imprenta, por vuelta del 
tercer cuarto del siglo $\mathrm{XV}^{2}$, pocos años antes del inicio de la ocupación de lo que sería más tarde América Latina. Para Dussel, 1492 es la fecha de nacimiento de la modernidad.

La Modernidad se originó en las ciudades europeas medievales, libres, centros de enorme creatividad. Pero "nació" cuando Europa pudo confrontarse con "el Otro" y controlarlo, vencerlo, violentarlo; cuando pudo definirse como un "ego" descubridor, conquistador, colonizador de la Alteridad constitutiva de la misma Modernidad. De todas maneras, ese Otro no fue "des-cubierto" como Otro, sino que fue "en-cubierto" como "lo Mismo" que Europa ya era desde siempre. De manera que 1492 será el momento del "nacimiento" de la Modernidad como concepto, el momento concreto del "origen" de un "mito" de violencia sacrificial muy particular y, al mismo tiempo, un proceso de "en-cubrimiento" de lo no-europeo. (DUSSEL, 1994, p. 8)

Es decir, el desarrollo y consolidación de esta modernidad es concomitante con el desarrollo del régimen capitalista de producción, ambos se contienen. Para Habermas (1994), el proceso de constitución de la modernidad, que lleva a relacionar la ley con la razón y la opinión pública, es lo que sustenta la moderna sociedad burguesa europea, y su institucionalidad. La emergencia de la modernidad en estos espacios sociales es al mismo tiempo la constitución de una centralidad sustentada en la razón y en la objetividad de los actos humanos. Esta separación entre razón/alma y cuerpo se inicia con Descartes en el siglo XVII, y con ello la larga marcha que lleva a la constitución de la moderna sociedad burguesa europea. La constitución del sistema capitalista en el contexto de la modernidad se presenta como una nueva forma de ver y pensar el mundo, y también de estudiarlo. El periodismo incorpora en su narrativa esta separación entre cuerpo/alma, entre lo externo y lo interno, entre lo objetivo y el sujeto. Al mismo tiempo esta práctica social, que en el tiempo deviene en periodismo, desarrolla la racionalidad como uno de sus ejes constitutivos en la construcción del texto;

2 En realidad, esto es desde la perspectiva de una "historia de occidente"; la imprenta surge en China a comienzos de los años 1000 . 
esta racionalidad es, al mismo tiempo, objetividad. Al hacerlo, este acto de narrar y contar hechos y situaciones se transforma en narrativa fundacional del mundo moderno europeo; esto es lo que nos fue narrado y contado durante largos años. Pero, veamos el "otro lado" de la misma, y observemos la realidad desde otra perspectiva. Al mismo tiempo, y con la conquista e invasión de 1492 - nacimiento de la modernidad según Dussel - estas epistemes y prácticas se imponen en los nuevos territorios ocupados, como parte del movimiento "expansivo" de las ideas y civilización europeas, es decir, como una forma de colonización del imaginario; la ocupación de vastos territorios implicó también la ocupación y conquista de las mentalidades de los pobladores originarios. Sin embargo, existía en estos territorios ocupados, formas de transmisión de informaciones y conocimientos que, obviamente, fueron silenciados, ignorados y rechazados.

En los espacios y territorios ocupados por el imperio español y el portugués - posteriormente también por el inglés y holandés -, existían "otros mundos" que expresaban por su vez otras formas de ver y pensar la realidad. Desde el Popol Vuh (1993) en Mesoamerica, pasando por los trabajos de Guaman Poma de Ayala (1980) en el Tiwantinsuyo inka-peruano, el Ayvu Rapyta de los Mbyá-Guaraní de Paraguay publicado por Cadogan (1992), y últimamente en trabajos de Reinaga (2010), Kopenawa (2015), Krenak (2019), y otros pensadores contemporáneos amerindios, estos entendimientos del mundo se presentan de manera muy diferente a aquellos expresados por la modernidad europea. En todos ellos podemos observar una estrecha relación entre cuerpo y alma, entre lo racional y los sentimientos, entre el sujeto y el objeto, entre cuerpos humanos animados y otros cuerpos no-humanos. Si, como señalábamos más atrás, el periodismo termina incorporando la racionalidad constitutiva de la sociedad burguesa europea, sería pertinente también pensar cómo y de qué manera el pensamiento no occidental, principalmente en América Latina, se incorpora en la práctica cotidiana, o por lo menos cómo y de qué manera ciertos elementos terminan incorporándose en ella. Esto implica al mismo tiempo un giro epistémico 
pasando a entender que es el sujeto - en su multiplicidad y diversidad - quien crea el objeto y consecuentemente la narrativa "objetiva"”. Así, la historia de América Latina también ha sido desde su conquista, la tentativa por imponer un modelo epistémico que separa cuerpo/alma y que sustenta a lo objetivo como fuente creadora de lo subjetivo; la ciencia normal europea ha sido el modelo a seguir, y consecuentemente el periodismo latinoamericano, para ser ciencia, debe acompañar este entendimiento y esta matriz euro-norteamericana.

El recorrido señalado más arriba está presente en la historia del periodismo latinoamericano. Cuando a inicios del siglo XX en algunos países de América Latina se presenta la "tensión" entre el "texto literario" y el "texto periodístico", es decir, una forma subjetiva u objetiva de contar los hechos, podemos señalar que la modernidad euro-norteamericana finalmente toma cuerpo en el periodismo de la región y se impone como modelo a seguir. Este entendimiento se ve reforzado con los cursos de periodismo en facultades y universidades de la región, orientados por este modelo (MEDITCH, 1999); ello significó la presencia de la forma o modo moderno de narrar el hecho social, separando el sujeto del "objeto periodístico”. Sin embargo, los fantasmas vilipendiados del pasado, brujos, magos, yatiris, xapuris y chamanes, no solamente continúan vivos, sino que saltan y bailan, gritan y cantan buscando recuperar, entre otras cosas, sus antiguas vivencias del tekopora ${ }^{4}$, del buen vivir o vivir bien.

\section{Colonialidad del poder, ¿y del texto periodístico?}

En las últimas décadas, comenzaron a surgir voces desde las márgenes y fronteras que cuestionan gran parte del pensamiento hegemónico construido desde la modernidad europea. Por un lado, tenemos los estudios poscoloniales que emergen como un movimiento intelectual que se

3 No entraré en la discusión de la filosofía occidental asociada a las distintas posturas "idealistas" y "materialistas"; estas no tienen igual entendimiento en el mundo no occidental al cual me estoy refiriendo.

4 Buen vivir, vivir bien, o tierra sin males, en Guaraní. 
desarrolla y consolida alrededor de las ideas de Edward W. Said, Homi K. Bhabha, Gayatri Spivak y R. Guha, entre otras. Este movimiento, impulsado por una diáspora académica proveniente del Oriente Medio y del Sur de Asia, a pesar de localizados en occidente, interpela fuertemente a Europa y Estados Unidos, al occidente imperial (BHAMBRA, 2014). Por otro lado, y desde América Latina, se articula un pensamiento estimulados por los textos citados más arriba, asimismo por investigadores como Aníbal Quijano, Edgardo Lander, Ramón Grosfoguel, Santiago Castro-Gómez, Arturo Escobar, Walter Mignolo, Zulma Palermo, por citar algunos, quienes recogiendo esas ideas y pensamientos colocadas en los textos apuntados, avanzan en una crítica a la colonialidad del poder, del saber y del ser. La característica de este movimiento es que la crítica la hacen desde América Latina, donde casi todos ellos están localizados. Estos aportes se insertan en el contexto de la emergencia de un movimiento social y político que reivindica, al mismo tiempo, otros modelos de desarrollo, otros modelos de pensar sustentando que otro mundo es posible. Sin ignorar los aportes del grupo de estudios poscoloniales, voy a centrar mi análisis de la relación sujeto-objeto inicialmente planteada, y desde la misma pensar el estudio del periodismo en la región. Para tal efecto, partiré de los trabajos críticos de Quijano (2014).

Este pensador peruano, establece como una de las grandes tareas a ser emprendidas, aquella destinada a la "critica al paradigma europeo de la racionalidad/modernidad", siendo que ésta es "indispensable, más aún, urgente" (QUIJANO, 2014, p. 65). Para este autor latinoamericano la alternativa es clara:

"En primer término, la descolonialización epistemológica para dar paso a una nueva comunicación intercultural, a un intercambio de experiencias y de significaciones como base de otra racionalidad que pueda pretender, con legitimidad, alguna universalidad. Pues nada menos racional, finalmente, que la pretensión de que la específica cosmovisión de una etnia particular sea impuesta como la racionalidad universal, aunque tal etnia se llame Europa Occidental. Porque eso, en verdad, es pretender para un provincialismo el título de universal." (QUIJANO, 2014, p. 65-66) 
La necesidad del momento es, según el autor, la destrucción de la colonialidad del poder mundial. Esto implica un proceso que tiene: i) la descolonización epistemológica, que daría paso a, ii) una nueva comunicación intercultural, iii) para un intercambio de experiencias y de significaciones como base en otra racionalidad que, iv) pretenda o busque, legítimamente, alguna universalidad.

Para este investigador es necesaria una descolonización epistemológica: pensar y estructurar la producción del conocimiento desde otra perspectiva que no la racional-moderna europea, alejados de la relación sujeto-objeto que este modelo introduce. Igualmente, es necesario un cuestionamiento a la totalidad única, asociada al pensamiento occidental, como punto de partida de toda creación de conocimientos; incluiría también aquí la creación y construcción de la información. Pero, al mismo tiempo, y paralelamente, es necesario sobrepasar la relación de subordinación e inferioridad de otras culturas que no la europea, que implica conceder a este pensamiento y conocimiento su universalidad. La modernidad produce, no sólo heridas coloniales, también produce heridas patriarcales (normas y jerarquías que regulan el género y la sexualidad) y heridas racistas (normas y jerarquías que regulan la etnicidad) (MIGNOLO, 2014). De esta manera se conforma un otro que es inferior, porque no pertenece al pensamiento y civilización europea, pero tienen el camino abierto para lograr llegar a la meta civilizatoria. Así fue construida América Latina, como el otro que debía seguir los caminos de Europa civilizada e ilustrada; de esta manera fue también pensada América Latina por sus élites económicas y políticas. Pero, no fue pensada de esta manera por sus habitantes y pueblos originarios. La relación sujeto-sujeto contenidas en los trabajos del Ayvu Rapyta Mbyá-Guarani, en el Popol Vuh maya-quiche, en los trabajos de Reinaga, Kopenawa y Krenak, nos dan a entender que la realidad presente en el universo no-occidental de la región es mucho más amplia, profunda y ha resistido a lo largos años de colonización.

A partir de esta descolonización epistemológica, tendríamos una nueva comunicación intercultural, un intercambio de experiencia, de 
conocimientos entre "pares", hombres y mujeres - inclusive aquellas/os no binarios -, entre culturas de manera horizontal, aprendiendo, criticando y observando sus particularidades. Esta comunicación intercultural da paso a un intercambio de experiencias y de significaciones como base “de otra racionalidad” según Quijano. En realidad, también es necesario discutir críticamente, cuestionar y radicalizar epistemológicamente el paradigma de la racionalidad en toda su extensión e implicancia. Si se cuestiona la relación sujeto-objeto que introduce el modelo de la racionalidad/modernidad europea, es decir, la idea de totalidad desde una perspectiva única y las demás como subordinadas e inferiores, también debemos cuestionar el paradigma en cuanto parte de la dicotomía racional-irracional, o racional-emocional. En consecuencia, una descolonización epistémica también debe implicar no solamente una crítica a la relación sujeto-objeto, también una crítica a la relación o a la construcción del pensamiento como resultado del desprendimiento de la relación racional-emocional. Quijano destaca que la represión colonial cayó sobre los distintos modos de conocer, de producir conocimiento, de producir perspectivas, imágenes y sistemas de símbolos, modos de significación, sobre los recursos, patrones e instrumentos de expresión formalizada y objetivada. A esto le siguió la imposición, por parte de los colonizadores, de sus propios signos y símbolos dominantes, sus creencias e imágenes, los cuales sirvieron como medios eficaces para impedir la producción cultural de los dominados/subalternizados y, al mismo tiempo, como medios eficaces de control social y cultural (QUIJANO, 2014). Lo que hemos tenido hasta ahora es la universalización de la racionalidad como modelo de pensamiento al cual llegar. Las demás formas de manifestaciones humanas que no sean éstas, no pueden ser o cobijar sujetos. En consecuencia, "las otras culturas son diferentes en el sentido de ser desiguales, de hecho, inferiores por naturaleza. Estas culturas sólo pueden ser "objetos" de conocimiento o de prácticas de dominación” (QUIJANO, 2014, p. 61).

De un nuevo dualismo, es como denomina Quijano a la propuesta que la modernidad europea introduce al pensamiento. Citando a 
Descartes, quien introduce la mutación del antiguo abordaje dualista entre cuerpo y no-cuerpo, que concluye, finalmente en la introducción de una nueva relación sujeto/objeto, apunta:

La razón no es solamente una secularización de la idea de alma en el sentido teológico, sino que es una mutación en una nueva identidad, la "razón/sujeto", la única entidad capaz de conocimiento "racional", respecto del cual el "cuerpo" es y no puede ser otra cosa que "objeto" de conocimiento. Desde ese punto de vista el ser humano es, por excelencia, un ser dotado de "razón", y ese don se concibe como localizado exclusivamente en el alma. Así el "cuerpo", por definición incapaz de razonar, no tiene nada que ver con la razón/sujeto. Producida esa separación radical entre "razón/sujeto" y "cuerpo", las relaciones entre ambos deben ser vistas únicamente como relaciones entre la razón/sujeto humana y el cuerpo/naturaleza humana, o entre "espíritu” y "naturaleza”. De ese modo, en la racionalidad eurocéntrica el "cuerpo" fue fijado como "objeto" de conocimiento, fuera del entorno del "sujeto/razón". (QUIJANO, 2014, p. 130).

Así, y a partir de las propuestas de Quijano señaladas más arriba, una descolonización epistemológica en el campo de la comunicación y del periodismo implicaría:

a. sobrepasar la relación sujeto-objeto en la comunicación y el periodismo.

b. sobrepasar la dicotomía que opone la relación racionalidad-emocionalidad. Es decir, el texto periodístico deberá ir más allá de la "tradicional" relación sujeto-objeto, que nos viene del paradigma euro-norteamericano, en el cual lo narrado es el objeto.

El entendimiento tradicional del periodismo como practica social en América Latina es aquel en el cual el redactor dialoga con un texto-objeto. Por su vez, la crítica a la racionalidad-modernidad europea posibilita, en el marco de ésta, establecer nuevas relaciones y nuevos entendimientos para el texto periodístico. Cuando pasamos a cuestionar y criticar el texto desde la perspectiva de su propia construcción objetiva - y no solamente en el marco o contexto de las representaciones construidas que 
expresan realidades -, la crítica a la relación sujeto-objeto, introduce un cuestionamiento ontológico al texto periodístico, una crítica a la esencialidad del mismo. Con estas consideraciones estaríamos sobrepasando a la "regla de oro" de la objetividad que durante tantos años comprimió -y aun comprime- al periodismo en América Latina. Inclusive algunas de las críticas más serias al paradigma euro-americano del periodismo producidas en la región, como la que encontramos en el excelente trabajo de Genro Filho (2012), no han conseguido sobrepasar los dos aspectos apuntados más arriba. La relación sujeto-objeto se presenta para Genro Filho como "uma relação na qual o sujeito não só produz o seu objeto como também é produzido por ele” (GENRO FILHO, 2012, p. 196); a pesar de la crítica - sumamente pertinente en varios momentos - a la "objetividad periodística" como parte de la ideología burguesa, observamos que aun se mueve - y dialoga -, en el paradigma de la modernidad euro-norteamericana del periodismo.

\section{Traducción/mediación cultural, texto y narrativa periodística}

¿Cómo y de qué manera es posible crear inteligibilidad entre las diversas experiencias del mundo, tanto las disponibles como las posibles? Es decir, ¿cómo y de qué manera saberes y prácticas en una determinada cultura, pueden ser inteligibles en otra? Es lo que el periodismo, de manera general, plantea e intenta resolver. Por otro lado, también tenemos en este contexto el problema del colonialismo del poder. Así, ¿cómo identificar aquellos residuos eurocéntricos heredados del colonialismo y presentes en los más diversos sectores de la vida colectiva como en la educación, la política, la cultura, etc., y al mismo tiempo cómo revitalizar la herencia latinoamericana interrumpida por el colonialismo? Estos dos momentos, uno relacionado al colonialismo interno (GONZÁLEZ CASANOVA, 2007) y otro a sus formas de superarlo, están presentes en el periodismo. Más específicamente, ¿cómo identificar en la práctica periodística aquellos elementos o residuos eurocéntricos presentes en 
el texto y narrativa periodística que constituyen herencias de un pasado colonial? Y, por otro lado, ¿cómo construir un periodismo desde las prácticas ancestrales presentes en la región e interrumpidas por el colonialismo y por el proceso posterior al mismo? En última instancia, lo que está en juego es cómo sustentar que una particular forma de narrar y contar un hecho social que emerge en una determinada cultura asociada a una región geográfica provinciana (CHAKRABARTY, 2000), se convierta en un modelo universal para todas las culturas. Es decir, una forma determinada y específica, particular de escribir y narrar, asume el carácter de una "técnica” universal. La historia del periodismo latinoamericano, contada desde una perspectiva colonial, no es nada más que el desarrollo de los procesos eurocéntricos en la región, que siguen y acompañan el modelo impuesto. Finalmente, es necesario formular una pregunta que necesariamente se encuentra asociada a estos dilemas: ¿Es posible que una particular forma de narrar y contar, se convierta en una forma y manera universal de narrar y contar? ¿O sea, un modelo, una forma de narrar, de contar el hecho social que sea independiente de la cultura de la cual originalmente emerge? Para intentar entender y dar cuenta de estas interrogantes, voy a trabajar con un concepto que permite apuntar un camino por donde transitar de manera que las preguntas formuladas puedan tener, si no una respuesta clara y contundente, por lo menos un nuevo horizonte hacia el cual orientar nuestras preocupaciones. Este concepto es el de traducción/mediación cultural.

\section{De las ausencias y las emergencias: Sousa Santos y el trabajo de traducción}

Una investigación sobre globalización desarrollada por Sousa Santos (2005) le lleva a la siguiente conclusión: la experiencia social en todo el mundo es mucho más amplia y variada de lo que la tradición científica o filosófica occidental conoce y considera importante para hacer visibles las iniciativas de movimientos alternativos y darles credibilidad; de poco sirve recurrir a las ciencias sociales tal y como la conocemos. Es necesario, entonces, un modelo diferente de racionalidad. Una de las tareas, 
sostiene este autor, es identificar "nuevas totalidades" al mismo tiempo de proponer nuevas formas de pensar esas totalidades. Si el mundo es una totalidad inagotable, caben en él muchas totalidades, todas ellas necesariamente parciales. Sousa Santos observa que, "desde el punto de vista de esta concepción del mundo, tiene poco sentido intentar captarlo por una gran teoría, una teoría general, ya que ésta presupone siempre la monocultura de una totalidad dada y la homogeneidad de sus partes" (SOUSA SANTOS, 2005, p. 174). La alternativa a la teoría general es el trabajo de traducción. La traducción es el procedimiento que consigue crear inteligibilidad entre las experiencias del mundo, sin el estatuto de totalidad exclusiva. El trabajo de traducción, según Sousa Santos, incide tanto sobre los saberes como sobre las prácticas y sus agentes. La traducción sería la forma de dar inteligibilidad a los saberes particulares, y a las prácticas sociales particulares, en su relación con otras culturas particulares. Lo universal es, desde esta perspectiva, una propuesta, la cual nunca se cierra y, para dar cuenta de este problema, la traducción actuaría como un momento de lo particular.

La traducción de saberes puede darse entre: i) diferentes saberes hegemónicos y no-hegemónicos, ii) entre diferentes saberes no-hegemónicos. Es en el trabajo de traducción entre diferentes saberes no-hegemónicos, en la inteligibilidad recíproca y en la posibilidad de agregación entre saberes no-hegemónicos, donde reside la importancia y la posibilidad de construir una contra-hegemonía. Es en la traducción de saberes no-hegemónicos donde se construye la contra-hegemonía. Los traductores de culturas deben ser los intelectuales de los procesos sociales, el arandu $k_{a} a t y^{5}$, y pueden encontrarse tanto entre los dirigentes sociales como entre los activistas de base y otros pensadores sociales.

Antes de continuar, me gustaría señalar rápidamente, algunas pistas que permitirán avanzar hacia una conceptualización del periodismo latinoamericano, desde las perspectivas que introduce Sousa Santos. La traducción que propone este investigador es aquella que se da entre saberes y prácticas sociales, cuyo resultado no puede constituirse en un

5 Conocimiento popular, en guaraní. 
nuevo conocimiento o práctica hegemónica. Es decir, si pensamos en el periodismo, es urgente pensar un proceso de traducción entre saberes, entre conocimientos generados en otras culturas que puedan ser inteligibles en la nuestra, y entre prácticas sociales, entre formas y maneras de operacionalizar el periodismo que no introduzca nuevamente prácticas hegemónicas. Si el conocimiento no es universal o no se sustenta en totalidades, si existe una miríada de conocimientos particulares asociados a culturas específicas, los saberes no pueden ser universales, sino más bien, existen varios universales y la traducción debe pensar e impulsar zonas de contacto no hegemónicas entre todas ellas. Si volcamos nuestra mirada hacia América Latina, y más específicamente hacia la región del Sur, con sus culturas variadas y múltiples, no podemos partir de la asunción de la existencia de una universalidad sea ésta eurocéntrica o no. Esto nos lleva a pensar en las particulares formas de contar un hecho social existente en la región, en las formas de difundir y construir informaciones que existen y dan visibilidad a las mismas. En una traducción sin hegemonía, el periodismo asume un papel de mediador social ${ }^{6}$.

\section{Los aportes de Fausto Reinaga y el "pensamiento local"}

Varias de las cuestiones colocadas por Sousa Santos, de alguna manera ya habían sido pensadas desde la región latinoamericana a lo largo de los siglos, inclusive contemporáneamente. Uno de estos pensadores y teóricos, Fausto Reinaga, introduce ciertos aspectos que considero importantes para la discusión. Por ejemplo, apunta que "en la piel blanca hay cultura india. El espíritu indio fulge y refulge en la piel blanca" (REINAGA, 2014, p.39) ${ }^{7}$. Reinaga sostiene que en la población blanca-mestiza latinoamericana se halla viva la cultura india. De igual manera, la población originaria de estos territorios incorpora la cultura

6 Este entendimiento es cualitativamente diferente al desarrollado por Lazarfeld \& Merton (1977) en su texto sobre el papel del periodismo. Se constituye en una crítica a la misma, y no busca equilibrios.

7 Este es un pensamiento que de alguna manera invierte al de Fanon (2009) quien señala que bajo la piel negra, se encuentra la máscara blanca; Fanon nada más está describiendo la esencia del colonialismo, al igual que Reinaga, quien apunta otra perspectiva también presente en esta relación colonial. 
del "otro". La primera es resultado de la presencia del blanco en estas regiones; la segunda, resultado de una invasión e imposición violenta. Y esto tiene que ver también con la lengua, con la escritura, y con la presencia de signos e imágenes existentes en una cultura, que busca ser impuesta o "traducida" para otra. Para el teórico aymara-boliviano, el idioma es pensamiento, sin palabra no es posible pensar y, cuando se piensa, se habla mentalmente. Esto lo refuerza cuando sostiene que el castellano y la cultura occidental "son meros elementos de traducción". Cuando el indio se expresa en "castellano, traduce su pensamiento elaborado en quechua o aymara al castellano” (REINAGA, 2014, p. 294). Es decir, para Reinaga, la traducción es un sistema mucho más complejo que el pasaje simple de la lengua indígena para el español.

Estos conceptos de Reinaga nos permiten pensar, al mismo tiempo, posibilidades de existencia y de implementación de un periodismo desde la región, que observe que el soporte no es simplemente una tecnología, es un complejo sistema cultural y social y, sobretodo, político. $\mathrm{Al}$ mismo tiempo, la escrita ha sido, a lo largo de todos estos años, un sistema que ha encubierto antes que revelado situaciones de extrema injusticia y pobreza en la región. Esto hace que lo simbólico tome la escena en la batalla de las narrativas (RIVERA CUSICANQUI, 2010).

Por otro lado, también podemos observar que la palabra, para determinados grupos en América Latina, es un elemento constitutivo de la propia vida. Es lo que se desprende de la cosmogonía Mbya-Guaraní, expresada en el Ayvu Rapyta (CADOGAN, 1992), donde la palabra crea la vida y es vida. La objetividad, en el sentido de la separación de alma-cuerpo, sujeto-objeto es entendida de una forma diferente a aquella que el pensamiento occidental sustenta. Podríamos pensar que esta relación sujeto-sujeto está presente solo en algunos géneros periodísticos como crónica o artículos de opinión. Aquí se nos presenta inmediatamente la pregunta, la noticia, continua siendo el género periodístico por excelencia? Si la propia construcción de la narrativa, sea ésta desde el soporte de la escritura, desde lo audiovisual u otro soporte, introduce 
desde un primer momento esta relación, es posible pensar en un periodismo diferente, o parafraseando a Mignolo, un periodismo otro.

\section{Hacia un nuevo periodismo en América Latina}

La necesidad y urgencia por pensar un periodismo que sea al mismo tiempo crítico y diferente al modelo eurocéntrico no es nueva en la región. En los medios, la disputa por contenidos, asimismo por el control de la propiedad, fue uno de los grandes ejes de disputa de diferentes perspectivas políticas e ideológicas, desde la colonia y durante los procesos independentistas del siglo XIX.

La crítica a la concentración de medios de comunicación en manos de sectores dominantes y de la oligarquía latinoamericana, que ganó fuerza en muchos países de América Latina en los últimos 20 años, también se apoyó decididamente, en una crítica a los contenidos manufacturados en estos medios. Consecuentemente, los cuestionamientos apuntan también hacia quienes construyen, elaboran o manufacturan dichos contenidos. A partir de estos dos elementos, la crítica al propio periodismo era solo una cuestión de tiempo. Y ella sucedió y sucede. La concentración de la propiedad de los medios de comunicación en pocas manos implica también la difusión de contenidos únicos, de particularidades que buscan transformarlas en universalidades. Siendo la sociedad latinoamericana múltiple y diversa, las voces críticas reclaman una democratización de la propiedad de los medios. Esta batalla hegemónica busca que se expresen las diferentes realidades sociales de la región. Tal es así, que en varios países ha surgido últimamente, desde el mismo poder, estrategias que buscan mitigar o disminuir desigualdades en la distribución del espectro radioeléctrico, asimismo de los medios más "tradicionales" en soporte papel. Legislaciones sobre medios de comunicación, sobre comunicación en general, periodismo y, últimamente sobre medios digitales y redes de internet, han sido los campos a partir de los cuales se ha procurado disminuir las asimetrías. La diversidad cultural de la región se instala inclusive en los aparatos legales, constituciones y legislaciones. 
En América Latina, en los últimos años emergen y fluyen iniciativas comunitarias que, durante varios años, décadas y siglos, han estado presentes en la población; son distintas formas y maneras de producción de la información. Estas prácticas y saberes que involucran a determinados sectores sociales, son particularidades que, en interacción con otras particularidades, saberes y prácticas en otras regiones, buscan un dialogo intercultural.

La propuesta acerca de la necesidad por desarrollar ciencias sociales nómadas (GARCÍA CANCLINI, 1990), o la de salir de los medios para las mediaciones (MARTÍN BARBERO, 1987), o aquella de buscar propuestas metodológicas distintas (DÍAZ BORDENAVE, 2011) o la de traducción (REINAGA, 2014; SOUZA SANTOS, 2005) constituyen un primer paso sumamente importante. La perspectiva de los estudios de periodismo a partir de estas consideraciones ha enriquecido el campo. Las universidades, facultades y carreras de comunicación y periodismo han sido también un permanente "fermento en la masa"; desde éstas han abierto nuevos caminos, apuntado nuevas críticas.

Sin embargo, y pesar del gran esfuerzo por encontrar caminos propios, desde el aporte de los pensadores apuntados más arriba, considero que es necesario avanzar un paso más. Las críticas a la propiedad y concentración de medios, asimismo a la construcción de contenidos, se da en el contexto del pensamiento de la racionalidad-modernidad eurocéntrica. Lo que necesitamos en América Latina, es avanzar hacia una crítica a este paradigma. La radicalidad necesaria no es sólo epistemológica, es también social. Descentrar al sujeto, pensar la realidad como un todo integrado entre sujetos, racionalidades y emocionalidades, puede apuntar una salida al presente impase en el periodismo. Contar un hecho social siempre ha sido una práctica diversa y múltiple en cualquier sociedad, y con mayor razón en América Latina. El giro epistemológico necesario al periodismo de la región, que exuda por los poros las experiencias de los pueblos originarios, de los sectores subalternos, mujeres, grupos LGTBI y otros sujetos y practicas populares, es aquel que considere la relación de contar para otros/otras/otres, y se invente a cada 
momento: pensar y exponerlo como una relación entre sujetos, no ya como una relación entre sujeto-objeto. Pensar como experiencias particulares que necesitan dialogar con otras formas de contar realidades, que necesitan dialogar con otras culturas. Para ello, el concepto de traducción y mediación cultural es sumamente pertinente.

Pero, me pregunto, ¿qué puede implicar pensar una relación entre sujetos para el periodismo? Y también, ¿qué cambios se introduce en el periodismo al pensar estrategias de traducción como forma de diálogo entre culturas y prácticas? No pensar solamente en una forma de narrar y contar el hecho social, a partir de normas y reglas centradas en la racionalidad euro-norteamericana; dar un giro y estructurarlas desde la realidad latinoamericana, desde las amplias formas con que se cuenta el hecho social de las/os sujetos en la región. La segunda pregunta, podríamos intentar responder desde la consideración que las totalidades y universalidades constituyen estrategias dominantes, formas hegemónicas de pensar y construir la realidad. Es decir, una manera particular de ver y observar el mundo, específica de una determinada parroquia o provincia, que busca imponerse como universal. Incorporar formas y maneras de narrar los acontecimientos de nuestros retirantes, e.gr. la producción de cordel en el nordeste brasileño, de los ñe’engas o dichos populares guaraní, de los relatos en el campo de la oralidad de los pueblos originarios, de las relaciones que se establecen entre sujetos y objetos que también son sujetos en las culturas de los pueblos originarios. Finalmente, pensar un periodismo desde esta relación implica pensar una nueva forma de periodismo, epistemológicamente radical. Y esto es no solamente necesario, también es urgente.

\section{Referencias}

BENÍTEZ, J. A. Los orígenes del periodismo en nuestra América. Buenos Aires: Lumen, 2000.

BHAMBRA, G. K. Poscolonial and decolonial dialogues. Poscolonial Studies, v. 17, n.2, p.115-121, dez. 2014.

CADOGAN, L. Ayvu Rapyta. Textos miticos de los Mbyá-Guaraní del Guairá. Asunción: CEADCU-CEPAG, 1992. 
290 PERIODISMO EN AMÉRICA LATINA: COLONIALIDAD Y TRADUCCIÓN CULTURAL

CHAKRABARTY, D. Privincializing Europe. Princeton: Princeton University Press, 2000.

DÍAZ BORDENAVE, J. Aportes a la comunicación para el desarrollo. Asunción: Instituto Latinoamericano de Comunicación para el Desarrollo-Secretaria de Información y Comunicación para el Desarrollo - SICOM, 2011.

DUSSEL, E. 1492. El Encubrimiento del otro. La Paz: Plural-UMSA, 1994.

FANON, F. Piel negra, máscaras blancas. Madrid: Akal, 2009.

GARCÍA CANCLINI, N. Culturas híbridas. México: Grijalbo, 1990.

GENRO FILHO, A. O segredo da pirâmide. Florianópolis: Insular, 2021.

GONZÁLEZ CASANOVA, P. Colonialismo interno (uma redefinição). In: A. BORON, A. A.; AMADEO, J.; GONZALEZ, S. A teoria marxista hoje. Problemas e perspectivas. Buenos Aires: CLACSO, 2007.

GUAMAN POMA DE AYALA, F. Nueva Crónica y Buen Gobierno. Caracas: Ayacucho, vol. I e II, 1980.

HABERMAS, J. Historia y crítica de la opinión pública. Barcelona: G. Gili, 1994.

KOPENAWA, D.; ALBERT, B. A queda do céu. São Paulo: Companhia das Letras, 2015.

KRENAK, A. Ideias para adiar o fim do mundo. São Paulo: Companhia das Letras, 2019. LAZARFELD, P.; MERTON, R. Comunicación de masas, gusto popular y acción social organizada. In: MURARO, H. (Org.). La comunicación de masas. Buenos Aires: Centro Editor de América Latina, 1977.

LEÓN-PORTILLA, M. Los antiguos mexicanos a través de sus crónicas y cantares. México: FCE, 1972.

MARTÍN BARBERO, J. De los medios a las mediaciones. Barcelona: G. Gili, 1987.

MEDITCH, E. CIESPAL: progreso y problema del comunicólogo. Chasqui, n. 67, p. 70-74, 1999.

MIGNOLO, W. Una concepción descolonial del mundo: conversaciones de

Francisco Carvallo con Walter Mignolo. Buenos Aires: Ediciones del Signo, 2014.

PALERMO, Z.; QUINTERO, P. Aníbal Quijano: Textos de fundación. Buenos Aires: Ediciones del Signo, 2014.

POPOL VUH. Las antiguas historias del quiche. México: FCE, 1993.

REINAGA, F. La revolución india. In: REINAGA, F. Obras Completas. Tomo II, v. 5. La Paz: Vicepresidencia del Estado Plurinacional de Bolivia, 2014.

RIVERA CUSICANQUI, S. Ch'ixinakax utxiwa: una reflexión sobre prácticas y discursos descolonizadores. Buenos Aires: Tinta Limón, 2010.

SOUZA SANTOS, B. Hacia una sociología de las ausencias y una sociología de las Emergencias. In: SOUSA SANTOS, B. El milenio huérfano. Madrid: Trotta, 2005.

Data de submissão: 14/09/2020

Data de aceite: 01/03/2021 